\title{
Study on Spatial Distribution Feature of Industry Population of Taiyuan from 1990
}

\author{
Jie Zhao ${ }^{1, \text { a }}$, Chuandong Wang ${ }^{2, b}$ \\ ${ }^{1}$ School of Urban Design, Wuhan University, Wuhan 430072, China; \\ 2 School of Urban Design, Wuhan University, Wuhan 430072, China. \\ a397858288@qq.com, b wcd66wcd@sina.com, ${ }^{\mathrm{C} y y y y @ c c c . c o m ~}$
}

Keywords: Spatial Distribution, Feature, Industry Population, Taiyuan

\begin{abstract}
There are a dozen of resource-based cities in China, which had been positioned as the prosperity ground of the heavy industry in the early days. With the improvement of the whole country's socio-economic level, the gradual expansion of the city, the upgrading of the secondary industry, these industrial city have gradually moved the heavy industry enterprises to the suburban area or even to the outskirts of the city region, and the corresponding spatial distribution of industry population has also shifted quickly during this period. In order to define the characteristics and regular pattern of the migration period of the second industrial population, provide consultations of industrial land layout and construction of the urban centers for these resource-based cities, this paper takes Taiyuan, a typical resource-based city as the study subject. Using the GIS technology to reflect the secondary industry population to micro-level between 1990 to 2010 to the land space of the city center, this research refines the evolution of the second industrial population size and density characteristics, summarizes the evolution of the moving pattern in order to promote and improve the urban construction and development of Taiyuan during the transition period.
\end{abstract}

\section{Introduction}

The spatial distributing changes of urban population have their inner regulations, and the spatial variation formed in population change is a general performance of our economy and society ${ }^{[1]}$. Spatial distribution characteristics of urban population is the most significant part for interpreting the urban morphology and internal structure models, and the evolution of population spatial distributing has directly act on the urban morphology and the usage of land ${ }^{[2]}$. And among them, the evolution and characteristics of industry population in spatial distributing have great influence on the land using arrangement of the second industry in cities ${ }^{[3]}$. Nowadays, most of the resource-based cities and heavy industrial bases in our country are adjusting their own industrial structures and actively completing industrial transformations. They are also relocating their spatial development of the second industry in cities and realizing harmonious interaction between industrial population and land. Therefore, the research of the evolution of population spatial distributing in cities provides some supports on the proper location of the second industry in spatial distributing during the industry transformation process, and is very important.

In western countries, researches on the population spatial distribution for industry originates from the 17th century, and western economists firstly put forward industrial population shift theory, concluding characteristic regulations and dynamic factors in industry characteristics of population migration, and doing a lot of researches on industry population in spatial distributing from macro level in economics, sociology and geography. However, with the improvement of western urbanization level, this kind of research lacks data supporting and cases on micro level, because of early improvement of industrial structure ${ }^{[4][5][6]}$.

As a typical resources city and one of the earliest heavy industrial bases at our founding of a republic, Taiyuan always relates its urban development with the second industry closely ${ }^{[7][8]}$. Thus, during the industry transition, Taiyuan puts more efforts on building perfect urban tertiary industry on the one hand, and constantly reconstructs of the second industry on the other hand. This paper uses the technology of GIS, takes streets and communities as research units, and makes spatial industry 
population in Taiyuan. And it also analyzes the distribution and evolution of industry population inside the city and provides related suggestions for its land layout planning in the second industry $^{[9][10]}$.

\section{Regional Overview}

General situation of Taiyuan. As military, cultural center in northern China and one of the heavy industry bases, Taiyuan is located in the north part of Shanxi Province, with a total area of $1460 \mathrm{~km}^{2}$ and total population of 4.3million(2014). It is the capital and the political, economic, cultural, traffic scientific and educational center of Shanxi Province. It is also the central city of Taiyuan urban agglomeration.

As the east part of Taiyuan borders on the Beijing-Tianjin-Hebei urban circle, Taiyuan has many advantages, such as traffic, industry and resources. Its development has huge potential. Based on this large urban agglomeration as the carrier, Taiyuan will not only be the rear base supporting the eastern and coastal areas but also the leading city promoting development of central and western areas. The transformation form resources city to the comprehensive city will be completed ${ }^{[11]}$.

Urban population change of Taiyuan. After the founding of China, the urban population of Taiyuan was 0.68 million in 1949, and the population expanded into 3.65million in 2010. The city's total population rose by 2.98 million and the growth rate of $439.46 \%$.

Table 1 1949-2010 Changes of residential population in urban area of Taiyuan

\begin{tabular}{cccc}
\hline & Population $(10,000)$ & $\begin{array}{c}\text { Average annual } \\
\text { growth rate }(10,000)\end{array}$ & $\begin{array}{c}\text { Average annual } \\
\text { growth rate (\%) }\end{array}$ \\
\hline 1949 & 50.81 & $/$ & $/$ \\
1953 & 82.5 & 7.92 & 12.88 \\
1964 & 120 & 3.41 & 3.46 \\
1982 & 158.25 & 2.13 & 1.55 \\
1990 & 195.75 & 3.75 & 2.15 \\
2000 & 255.8 & 6.01 & 2.71 \\
2010 & 285.01 & 2.92 & 1.09 \\
$1949-2010$ & $/$ & 3.84 & 2.9 \\
\hline
\end{tabular}

Industry evolution in Taiyuan.After the reform and opening, since saturation of industrial development and expansion of consumer services, the output value proportion of tertiary industry has been constantly rising in Taiyuan and that of the second industry has been gradually declining. With year of 1996 as a turning point, the industrial structure in Taiyuan is transformed from "secondary, primary, tertiary " industry leading industrial structure into " tertiary, secondary ,primary" service industry leading industrial structure, which continues till today.

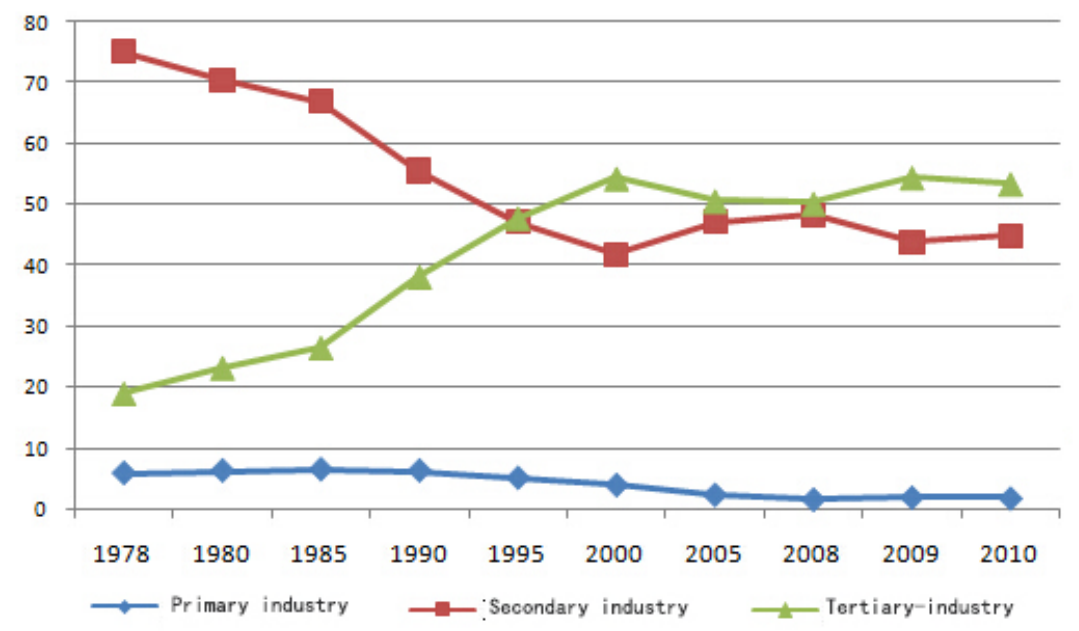

Fig. 1 1978-2010 annual evolution of the Industrial Structure in Taiyuan 


\section{The Spatial Distribution and Evolution Characteristics of Industry Population in Taiyuan}

\section{The spatial distribution and evolution of industrial population size in Taiyuan.}

1) The evolution of industrial population size in urban area of Taiyuan

In the years between 1978 and 2010, the industry population of Taiyuan grew firstly and then declined, reaching the peak of 87.2 billion in 1996 and falling down to 66150 in 2000. Then industrial population was in a state of fluctuation, accounting 569339 in 2010.

2) The evolution of spatial distribution in streets' industrial population

From 1990 to 2000, we can find the following stages of the spatial distribution in industry population after the industrial population spatialization of streets in Taiyuan.

(1) The first stage: Industry population in old town increased in centralization from 1999 to 2000.

In this period, Taiyuan was in adaptation and adjustment of the social economy transformation, and the increase in urban industry population was very stable, while in old town, the industry population increased obviously, much different from the outside. As the traditional coal processing and of iron and steel production base, Yingze district, Wanbolin district and Jiancao district, with a good development foundation, developed in industry rapidly and the population increased following industry. And because of the limitation in commuting demand and the idea and level urban construction, the location of Industry Parks are around the old town, forming "besieged city", and industry population there gathered constantly.

(2) The second stage: The scale of industry population size in old town decreased rapidly and increased slowly outside.

Taiyuan was in the exploration and experiment of industrial structure transformation from 2000 to 2005. And with the rise of the tertiary industry, population in the second industry began to transform into the service industry. However, Industrial Parks were guided by industrial policy and had to move out of the old town, which caused huge spatial differences in the growth of industry population.

Among them, industry positioning in old town changed from the second industry oriented to the tertiary industry, and the large-scale integration and relocation of industrial land caused the sharp falling in old town population. Outside the old town, there were many new industrial parks and development area in Wanbolin district and Jiancao district, they accepted old industrial enterprises and relocated proper land for living, which increased the population slowly. With the migration of Industrial land layout, Population in Taiyuan city's suburb loss seriously, presenting the negative growth.

(3) The third stage: Industry population recovered slightly in old town, and urban suburban population was in stable growth from 2006 to 2010

From 2005 to 2010, with the support and guidance of our State Policies, the transformation of economy and society in Taiyuan was speeded quickly and industrial structure was in stable. During this process, because of the construction of new high-technology development area, Taiyuan's industry population was migrating to this new area. The high speed increase in population was some of the streets near the suburb, such as the new high-technology development area and Longcheng district, etc, and area with an industry population growth rate over $5 \%$ became the main area for population growth. At the same time, the living environment in old town was improved, and some of the industry population chose to come back. Although, population decreased in the west of old town, north-east area had a slight recovery. Differences of population growth rate increased in different streets (countryside and town).

In this period, Wanbolin District within the jurisdiction of Taiyuan has the highest annual growth rate in industry population. And because they strengthened the reconstruction of living environment, speeded the development in industry and real estate, and upgraded in industrial structures, this district has built a huge Eco-Industrial Park (such as Taiyuan industrial Park, Stainless Steel Park etc), which providing more space for life and production, and the industry population gathered quickly and size increased rapidly. 

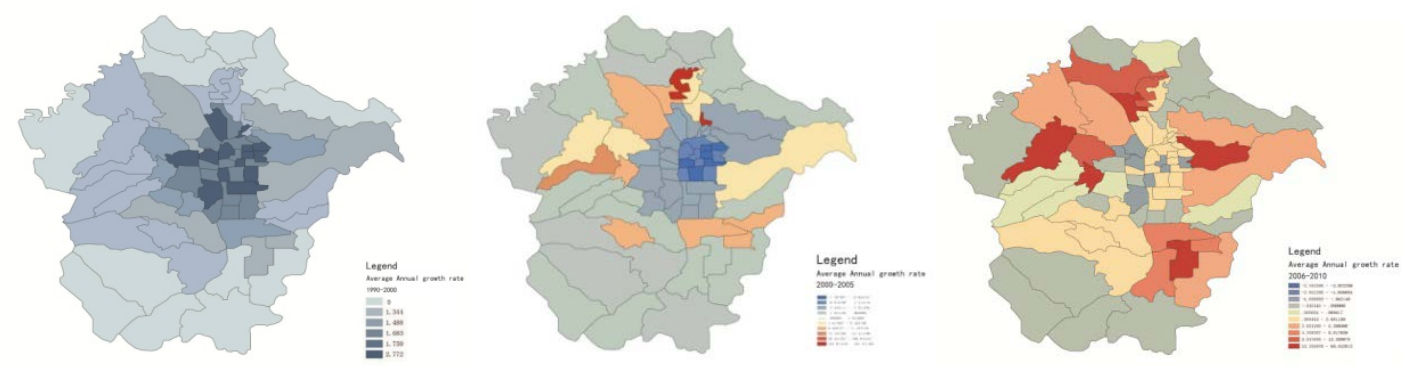

Fig. 2 1990-2010 The spatial distribution of industry population growth in Taiyuan

\section{Spatial distribution evolution of population density in Taiyuan.}

1) Industrial population density evolution in Taiyuan urban area

From all previous census data and Taiyuan Yearbook, it can be seen that the industrial population density in Taiyuan urban area went into a state of twists and turns in the study period.

From year 1990 to 1995, influenced by economic development, industry and population sustained rapidly developed, but the conservation strategy of city development limited the urban construction, which led the sustained growth of urban industrial population density.

From year 1995 to 2004, through policy of industrial structure adjustment and related planning method, a large number of industrial people turned to engage in business and service industries, so there was a steep fall in industrial population density.

From year 2004 to 2010, development pattern of leaning to the third industry was changed in Taiyuan. The secondary and third industries were equally emphasized. The mutual construction of high-tech zone and industrial park led a slow rising in industrial population density.

2) Spatial distribution evolution of population density in Taiyuan sub-district area

From year 1990 to 2010, population density in Taiyuan sub-district area had experienced the distribution patterns of single center to concentric circles and then to multi-centers.

(1) From year 1990-2000, the industry population density was high in center but low in periphery with a single center concentration.

From year 1990 to 2000, the population density in old urban area was obviously higher than that of other areas. On less than $12.5 \%$ of land, $75 \%$ industry population in Taiyuan was concentrated. The population density showed a single center concentration state with high in center, low in periphery, high in urban area and low in suburban area. It indicated that, at this stage, as the center of the politics, economy and culture, the old urban area had a strong attractiveness to population and led a large number of people concentrated in it.

(2) From year 2000 to 2005, the industry population density greatly decreased in old urban area and increased in external area with a balanced distribution and typical pattern of concentric circles.

As the adjustment of industrial structure in Taiyuan and the orientation transformation of old urban area, the industrial population Taiyuan shifted to the service industry and business industry, so the industrial population had fallen sharply. The government began to renovate the pollution and traffic problems caused by concentration of industry and enterprises in urban area. Industrial parks began be moved to outside of the old urban area and the population was led to move out too. The population density difference between old urban area and external area shrinked. The population distribution was more balanced with typical pattern of concentric circles.

(3) From year 2005 to 2010, the industrial population density in old urban area kept stable and that in near suburban area increased with a pattern of multi-center distribution.

With the stability of the industrial structure and the basic success of industry and enterprises' transformation from labor-intensive to technology-intensive, as well as the out moving of large traditional coal and energy industrial park, near suburban area became the concentration center for industrial population and population density in old urban area kept stable. Industrial population in far suburban area was introduced to near suburban area and was distributed as the distribution of large industry and enterprises. The multi-centered industrial population distribution was formed. 

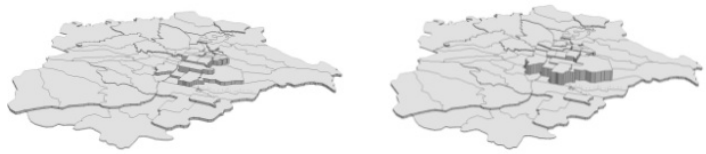

2000

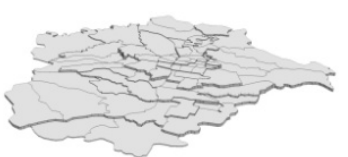

2005

2010

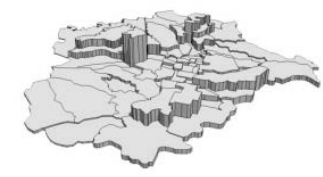

Fig.3 1990-2010 The spatial distribution of industry population density in Taiyuan

\section{Spatial equilibrium analysis of industrial population in Taiyuan}

In this article, concentration factor and unbalanced index are used to analyze the spatial distribution of population is relatively balanced or relatively concentrated ${ }^{[12]}$.

The formula of concentration factor is:

$$
C=\frac{1}{2} \sum_{i}|X i-Y i|
$$

In this formula, $\mathrm{C}$ represents the population concentration factor; $\mathrm{X}$ is the ratio of population of a certain region in the total population; $\mathrm{Y}$ is the ratio of corresponding land area in total area. The smaller the $\mathrm{C}$ value is, the more balanced the population distribution in this region.

The formula of unbalanced index is:

$$
\boldsymbol{U}=\sqrt{\frac{\sum_{i=1}^{n}\left[\frac{\sqrt{2}}{2} *(X i-Y i)\right]^{2}}{n}}
$$

In this formula, $\mathrm{U}$ represents the unbalanced index; $\mathrm{n}$ is the number of regions (administrative region or statistical region); $\mathrm{X}$ is the ratio of every regional population in the total population; $\mathrm{Y}$ is the ratio of every regional area in the total land area. The smaller $U$ value is, the more balanced the population distribution is.

According to population data of Taiyuan, concentration index and unbalanced index of industrial population distribution in year of 1990 to 2010 can be calculated:

Table 2 Industry population concentration and uneven index of Taiyuan

\begin{tabular}{cccc}
\hline & 1990 & 2000 & 2010 \\
\hline $\begin{array}{c}\text { Concentration } \\
\text { Index }\end{array}$ & 0.691 & 0.193 & 0.393 \\
Uneven Index & 0.057 & 0.004 & 0.032
\end{tabular}

It can be seen from the table that the concentration index recovered slightly after great slashing and unbalanced index continues to decline. Combined with spatial distribution characteristics of industrial population in Taiyuan, it can be found that, from year of 1990 to 2010, spatial distribution of industrial population in Taiyuan have experienced the process from a single center concentration to multiple-layer balance and then to multi-center concentration. So the concentration index rises after fall. The constant fall of unbalanced index indicates that, at this stage, industrial population distribution in urban area continues to spread and population density difference if every sub-district continues to decrease.

\section{Summary}

From the analysis above, we can find that, during the years between 1990 and 2010, the spatial distribution of industry population in Taiyuan had the following characters:

(1) Industrial population scale changed in fluctuation, and the differences existed among the areas. The industry population in old town gradually reduced.

From the whole, industry population in cities was in a stable growth, but the distribution was in imbalance. There were the obvious spatial difference characteristics for industry population growth inside the cities. From the year 1990 to 2000, due to factors of geographical conditions and economic development, the layout of industry population was in a tendency of strong regional centralization, and most of them were centralized in old town, belonging to single central growth. From 2000 to 
2005, the development areas in suburb attracted more industry population, while the negative growth appeared in old town. The spatial distribution of industry population was imbalance and showed the model of concentric zone. From 2005 to 2010, population in suburb increased rapidly.

(2) Industry population density firstly increased and then decreased form single centralization to multi-centralization structure, and the density in urban fringe increased significantly.

With the development of the society, population density in Taiyuan experienced a trend of rising first then falling, and its mechanism was similar to other cities in industry population density. At first, the density was over increased with the influence of economic policies, then, in industry transformation, the density decreased with the help of adjustment in administrative division, urban planning and related industrial policies, and the industrial structure was recovered again and industry population increased with the development of economy.

\section{References}

[1]. Lee Y. An allometric analysis of the US urban system: 1960- 80[J].Environment and Planning A, 1989, 21:463- 476.

[2]. Wang F, Zhou Y. Modelling urban population densities in Beijing(1982- 1990): suburbanization and its issues[ J]. Urban Studies,1999, 36:271- 288.

[3]. Chunshan Zhou.Theoretical study of the urban population movement[J].Urban Planning.1996(3):34-40.

[4]. Ogrosky, C E. Population estimates from satellite imagery [J].American Society of Photogrammetry, Journal of,1975,41:707-712.

[5]. Committee on Population, National Research Council. Population and Land Use in Developing Countries[M].1993.

[6]. Paul Waddell. UrbanSim: Modeling Urban Development for Land Use, Transportation, and Environmental Planning $[\mathrm{J}]$. Journal of the American Planning Association,2002,68 (3) :297-314.

[7]. ZhuYirong, TianHua, QiLiyan. The Effects of New City Development on Population and Industrial Distribution in Beijing [J] . Planners,2010 (8):113 -117.

[8]. Shanyu Zhang. Industrial restructuring and Shanghai's urban population redistribution [J].Journal of East China Normal University(Philosophy and Social Sciences), 2001(7): 85-90.

[9]. Jian Cheng. Beijing's population and urban construction sites - Beijing city overall planning and implementation of population and decades of urban construction land development [J]. Beijing observation,2002 (10): 14-18.

[10]. Fuming Zhang, Puqiu JIng. Industrial Development and urbanization development of resource-based regional center of the city - in Taiyuan city[J]. China Population Resources and Environment,2007(4).

[11]. Hui Wu, Chunxiang Zhang. The nature of the evolution of Taiyuan city planning [J]. Urban and Rural Development,2012(3).

[12]. An Zhang, Qingwen Qi. Study based on GIS of the population spatial structure within the city.Progress in Geography,2007,26(1):95-105. 